УДК 358.3:528

Віталій Володимирович Зуйко (кандидат військових наук, доцент)

Сергій Валентинович Зотов

Олександр Анатолійович Кошлань

Національний університет оборони Украӥни імені Івана Черняховського, Київ, Украйна

\title{
МЕТОДИКА ОЦІНЮВАННЯ НАДІЙНОСТІ ВИКОНАННЯ ЗАХОДІВ ТОПОГЕОДЕЗИЧНОГО ЗАБЕЗПЕЧЕННЯ
}

\begin{abstract}
У статті розглянутий підхід до очінювання надійності виконання заходів з топогеодезичного забезпечення шляхом представлення їх як системи масового обслуговування, яка дозволяє оцінити ймовірність обслуговування споживача відповідною інформацією та встановити, що виконання завдання не буде зірваним через відмови за наступними вхідними параметрами: наявність у банку даних топогеодезичної інформації на територію, яка необхідна споживачу; доступність та безвідмовна робота каналів зв'язку за якими проходить изиркулячія топогеодезичної інформації; наявність необхідноі кількості спеціалістів, які наповнюють бази даних топогеодезичною інформацією відповідно до існуючих вимог до ї̈ точності, наочності та оперативності.
\end{abstract}

Ключові слова: топогеодезичне забезпечення; ефективність заходів; система масового обслуговування; надійність системи.

\section{Вступ}

Успішне ведення бойових дій у значній мірі залежить від правильної оцінки ситуації, яка склалася в районі збройного конфлікту, як перед його початком так і в ході його ведення. Досвід участі Збройних Сил України в операції Об’єднаних сил (АТО) показав, що ефективність застосування систем управління військами i зброєю знаходиться у прямій залежності від якості інформаційного забезпечення, i зокрема від повноти та достовірності забезпечення військ (сил) вихідними топогеодезичними даними, які використовується штабами і військами. Так, в умовах ведення збройної боротьби процес створення, доведення до військ та використання топогеодезичних даних $є$ безперервним та має свої особливості і складності. Потреба у цих даних прив'язана до району проведення бойових дій та повинна бути актуальна на будь-який момент часу [1]. Особливістю діяльності топографічної служби $\epsilon$ те, що вона крім виконання завдань топогеодезичного забезпечення військ (сил) в операціях (бойових діях) $є$ також безпосереднім виконавцем і виробником усіх видів топогеодезичної та картографічної продукції для потреб Збройних Сил України (та інших силових відомств) [2].

Досвід проведення операції Об'єднаних сил (АТО) показав що необхідність забезпечення надійності виконання заходів 3 топогеодезичного забезпечення військ (сил), вимагає обгрунтованого оцінювання ймовірності отримання інформації про місцевість штабами і військами всіх рівнів.

Постановка проблеми. Ефективність системи топогеодезичного забезпечення залежить від наступних показників:

точності топогеодезичної інформації;

оперативності виготовлення та доведення топогеодезичної інформації до користувачів;

надійності топогеодезичного забезпечення.
Крім ефективності функціонування система характеризується деякими показниками надійності функціонування, які поділяються на два типу. Технічні показники надійності - це показники, пов'язані 3 параметрами системи, вони характеризують переходи системи 3 одного стану в інший і безпосередньо не відносяться до кінцевих результатів роботи. Наприклад, такими показниками $\epsilon$ інтенсивність відмов або інтенсивність відновлення елементів системи. Оперативні показники надійності - це показники, які характеризують вплив даного стану на кінцевий ефект, тобто на критерії системи. До них відносяться, наприклад, ймовірність безвідмовної роботи системи [3].

У зв'язку 3 цим, актуальною $\epsilon$ наукова проблема оцінювання ймовірності забезпечення топогеодезичною інформацією як фактору надійності функціонування системи топогеодезичного забезпечення.

Аналіз останніх досліджень і публікацій. Питанням оцінювання ефективності системи топогеодезичного забезпечення, вибору крітерію та показників присвячені роботи $[3,4]$. За допомогою розроблених підходів встановлені показники за якими проводиться оцінювання заходів топогеодезичного забезпечення. Окреслені праці висвітлили фундаментальні підходи до питань оцінювання вищезазначених заходів, але питання оцінювання надійності як складової ефективності під час виконання заходів топогеодезичного забезпечення дій військ (сил) розглянуті не були.

Мета статті полягає у оцінюванні надійності виконання заходів 3 топогеодезичного забезпечення шляхом представлення їх як системи масового обслуговування, яка дозволяє оцінити ймовірність обслуговування споживача відповідною інформацією. 


\section{Виклад основного матеріалу дослідження}

Оцінювання ефективності функціонування будь-якої системи виконується за допомогою векторного критерію $\mathrm{W}=\left(\mathrm{W}_{1}, \mathrm{~W}_{2}, \ldots, \mathrm{W}_{\mathrm{n}}\right)$, який $\epsilon$ показником якості роботи системи. Складовими вектору $\mathrm{W}$ можуть бути різні характеристики, а саме: час надходження інформації $\mathrm{W}_{1}$, ймовірність виконання завдання $\mathrm{W}_{2}$, тощо.

Розглянемо більш докладно положення щодо надійності функціонування системи. Топогеодезичне забезпечення, як i будь-яка система характеризується вектором параметрів $\mathrm{X}=\left(\mathrm{X}_{1}, \mathrm{X}_{2}, \ldots, \mathrm{X}_{\mathrm{k}}\right)$, який належить деякій множині $\mathrm{X}$ i визначає стан системи. $\mathrm{Y}$ найпростішому випадку це параметри, які визначають наявність та працездатність елементів системи. Внаслідок виходу елементів зі строю або ïx відновлення параметри змінюються в часі $\mathrm{t}$, тобто має місце випадковий процес зміни станів $\mathrm{X}(\mathrm{t})$, який має назву траєкторії системи.

Множину станів системи позначимо: $\{\mathrm{g}\}=\mathrm{G}$, де g - траєкторії процесу зміни станів. Повній працездатності системи відповідає деяка траєкторія, яку позначимо $\mathrm{g}_{0}$.

Крім параметрів, пов'язаних 3 надійністю системи, існують параметри $\mathrm{y} \in \mathrm{Y}$ зовнішніх факторів: характеристики погодних умов, місцевості, особливості району ведення бойових дій, вплив противника на елементи системи, тощо. Вони також можуть змінюватися у часі, утворюючі подібні траєкторії $\mathrm{y}(\mathrm{t})$, які належать множині $\mathrm{Y}(\mathrm{y} \in \mathrm{Y})$.

Так у загальному вигляді ефективність функціонування системи залежить від параметрів системи, а також від інших зовнішніх факторів, тобто $\mathrm{W}(\mathrm{t})=\mathrm{W}(\mathrm{x}(\mathrm{t}), \mathrm{y}(\mathrm{t}))$.

При деяких нежорстких обмеженнях функцію $\mathrm{W}(\mathrm{x}(\mathrm{t}), \mathrm{y}(\mathrm{t}))$ можливо представити у вигляді множини, виділивши в якості співмножника номінальну ефективність системи $\mathrm{W}_{0}$, тобто узагальнену ефективність системи при повній працездатності.

Номінальна ефективність системи $\mathrm{W}_{0}$ не залежить від надійності тому, що вона визначена для стану “абсолютної надійності" (повної працездатності системи): $\mathrm{W}(\mathrm{x}, \mathrm{y})=\mathrm{R}(\mathrm{x}, \mathrm{y}) \mathrm{W}_{0}(\mathrm{y})$ або $\mathrm{R}(\mathrm{x}, \mathrm{y})=\frac{\mathrm{W}(\mathrm{x}, \mathrm{y})}{\mathrm{W}_{0}(\mathrm{y})}=\mathrm{K}_{\mathrm{e \phi}}$, де $\mathrm{K}_{\mathrm{e \phi}}-$ коефіцієнт збереження ефективності.

У теорії надійності цей коефіцієнт розглядається як показник оперативної надійності системи. Він має фізичний зміст - показує, яка частина номінальної ефективності системи зберігається при виході 3 ладу іiі елементів, які характеризують працездатність. При цьому, оскільки найбільша ефективність системи має місце при $\mathrm{W}=\mathrm{W}_{0}$, то вочевидь, що $0 \leq \mathrm{K}_{\mathrm{e \phi}} \leq 1$.

Якщо ефективність системи оцінюється по ймовірності виконання нею визначеного завдання, то $\mathrm{K}_{\text {еф }}$ приймає значення ймовірності того, що виконання завдання не буде зірваним через відмови. При оцінюванні функціонування системи топогеодезичного забезпечення надійність іiі визначається, як ймовірність своєчасного доведення до споживачів топогеодезичної інформації.

Встановимо, що надійність функціонування системи топогеодезичного забезпечення буде оцінюватись величиною коефіцієнту збереження ефективності.

У загальному випадку встановимо, що надійність функціонування системи топогеодезичного забезпечення описується трьома параметрами:

$\mathrm{x}_{1}$ - наявністю у банку даних топогеодезичної інформації на територію, яка необхідна споживачу;

$\mathrm{x}_{2}$ - кількістю спеціалістів, які наповнюють бази даних топогеодезичною інформацією;

$\mathrm{x}_{3}$ - кількістю каналів зв'язку за якими проходить циркуляція топогеодезичної інформації, яка необхідна споживачам.

Будемо вважати також, що системи топогеодезичного забезпечення відноситься до системи масового обслуговування, надійність функціонування якої розраховується за формулою.

$$
\mathrm{W}_{2}=\sum_{\mathrm{j}} \frac{\mathrm{n}_{\text {Bxj }} \mathrm{P}_{0 \mathrm{j}} \mathrm{K}_{\mathrm{j}}}{\mathrm{N}_{0}}=\sum_{\mathrm{j}} \frac{\mathrm{n}_{0 \mathrm{j}}}{\mathrm{N}_{0}} \mathrm{~K}_{\mathrm{j}}
$$

де: $\mathrm{n}_{\mathrm{oj}}-$ число вимог $\mathrm{j}-\mathrm{i}$ групи, що задовольняється повністю справною системою;

$\mathrm{n}_{\text {вхј }}$ - число вимог j-ї групи, що поступили на вхід системи;

$\mathrm{N}_{0}$ - загальна кількість отриманих системою вимог.

Відношення $\frac{\mathrm{n}_{0 \mathrm{j}}}{\mathrm{N}_{0}}-$ визначає долю вимог $\mathrm{j}-\ddot{\mathrm{i}}$ групи в загальній кількості вимог, яка обслуговується повністю справною системою. Відповідно, воно визначиться як вірогідність $\mathrm{K}_{\mathrm{j}}$, що усереднена за всіма вимогами.

Вимогою будемо вважати номенклатурний аркуш електронної карти, який необхідно доставити споживачу.

Стосовно системи яка розглядається, коефіцієнт $\mathrm{K}_{\mathrm{j}}$ в (1) буде мати зміст ймовірності доведення одного номенклатурного аркуша електронної карти, при якому повністю однаково здійснюється обробка тільки таких номенклатурних аркушів, які оброблялися в суміжні проміжки часу. Позначимо цей інтервал dt, доля dt в загальній кількості $\frac{\mathrm{dt}}{\mathrm{t}_{\mathrm{p}}}$, де $\mathrm{t}_{\mathrm{p}}$ - загальний час виконання задачі.

Даний коефіцієнт $\mathrm{K}_{\mathrm{j}}$ буде відповідати безперервній функції $\mathrm{K}(\mathrm{t})$, де $\mathrm{t}$ - дійсний час. Тому виникає завдання визначити дану функцію.

Оскільки кожний номенклатурний аркуш 
послідовно проходить всі етапи обробки (створення/оновлення, зберігання, доставку), відповідно, контур обслуговування включає всі ці компоненти і

$$
\mathrm{K}_{\mathrm{t}}=\mathrm{P}\left(\omega_{\mathrm{xp}}\right) \mathrm{P}\left(\omega_{\mathrm{H}} / \omega_{\mathrm{xp}}\right) \mathrm{P}\left(\omega_{д} / \omega_{\mathrm{xp}} \omega_{\mathrm{H}}\right)
$$

де: $\omega_{x р}-$ подія, яка пов'язана 3 не ураженням автомобіля штабного топографічного (АШТ) групи топогеодезичного та навігаційного забезпечення (ТГНЗ);

$$
\mathrm{P}\left(\omega_{\mathrm{xp}}\right) \text { - ймовірність не ураження АШТ групи }
$$
ТГНЗ;

$\omega_{\text {н }}$ - успішне завантаження 3 бази даних номенклатурного аркушу електронної карти, або створення топографічного документу;

$\mathrm{P}\left(\omega_{\mathrm{n}} / \omega_{\mathrm{xp}}\right)$ - ймовірність завантаження 3 бази даних номенклатурного аркушу електронної карти, або створення топографічного документу при умові збереження АШТ групи ТГНЗ;

$\omega_{\text {д }}$ - успішна доставка номенклатурного аркушу електронної карти споживачу;

$\mathrm{P}\left(\omega_{д} / \omega_{\mathrm{xp}} \omega_{\mathrm{H}}\right)$ - ймовірність доставки при умові збереження АШТ групи ТГНЗ та успішному завантаженню з бази даних номенклатурного аркушу електронної карти, або створення топографічного документу.

Будемо вважати, що знищення АШТ та ураження особового складу групи ТГНЗ взаємно не пов'язані між собою, що дозволяє вважати ці події незалежними. Тоді формула (2) прийме вигляд:

$$
\mathrm{K}(\mathrm{t})=\mathrm{P}\left(\omega_{\mathrm{xp}}\right) \mathrm{P}\left(\omega_{\mathrm{H}}\right) \mathrm{P}\left(\omega_{\text {д }}\right)
$$

Оцінювання ймовірності не ураження АШТ групи ТГНЗ та ймовірність своєчасного відновлення апаратної та інформаційної складової групи ТГНЗ здійснюється за формулою:

$$
\mathrm{P}\left(\omega_{\mathrm{xp}}\right)=1-\left(\mathrm{R}_{0} \mathrm{R}_{1}\right)^{\mathrm{k}}\left(1-\mathrm{R}_{2}\right)
$$

де: $\mathrm{R}_{0}$ - ймовірність потрапляння АШТ групи ТГНЗ в зону ураження зброєю;

$\mathrm{R}_{1}$ - умовна ймовірність ураження;

$\mathrm{R}_{2}$ - ймовірність своєчасного відновлення апаратної та інформаційної складової групи ТГНЗ;

k - кількість підгруп групи ТГНЗ.

В процесі отримання 3 бази даних номенклатурного аркушу електронної карти, або створення топографічного документу приймають $\mathrm{x}_{2}$ спеціалістів, які працюють паралельно. Якщо вважати, що ймовірність безпомилкової роботи i -го спеціаліста $\mathrm{R}_{\mathrm{i}}$ буде виражатися:

$$
\mathrm{R}_{\mathrm{i}}=\mathrm{e}^{-\int^{\mathrm{t}} \mathrm{c}(\mathrm{t}) \mathrm{dt}}
$$

де: $\mathrm{c}(\mathrm{t})$ - частота появи помилок, то ймовірність безпомилкової роботи всього колективу складатиме:

$$
\mathrm{R}_{\mathrm{H}}=1-\prod_{\mathrm{i}=1}^{\mathrm{x}_{2}}\left(1-\mathrm{R}_{\mathrm{i}}\right)
$$

тоді

$$
\mathrm{P}\left(\omega_{\mathrm{H}}\right)=\mathrm{E}_{\mathrm{H}} \mathrm{R}_{\mathrm{H}}=\mathrm{E}_{\mathrm{H}}\left(1-\prod_{\mathrm{i}=1}^{\mathrm{x}_{2}}\left(1-\mathrm{R}_{\mathrm{i}}\right)\right)
$$

де: $\mathrm{E}_{\mathrm{H}}-$ ваговий коефіцієнт, який відповідає відносній ефективності роботи спеціалістів.

Приблизно його значення можна вважати спадаючим пропорційно виходу 3 ладу особового складу $\mathrm{E}_{\mathrm{H}}=\frac{\mathrm{x}_{2}}{\mathrm{x}_{2 \max }}$.

Якщо вважати, що спеціалісти схильні до помилок в однаковій мірі, тобто частота виникнення помилок у всіх спеціалістів однакова та крім цього, незалежна від часу, то ймовірність успішного завантаження з бази даних номенклатурного аркушу електронної карти, або створення топографічного документу:

$$
\mathrm{P}\left(\omega_{\mathrm{H}}\right)=\frac{\mathrm{x}_{2}}{\mathrm{x}_{2 \max }}\left(1-\left(1-\mathrm{e}^{-\mathrm{ct}}\right)^{\mathrm{x}_{2}}\right)
$$

Доставка номенклатурного аркушу електронної карти здійснюється по $\mathrm{x}_{3}$ каналах зв'язку, які працюють одночасно, формула для оцінки ймовірності їх безвідмовної роботи подібна (8), але замість (с) буде присутнім інтенсивність відмов каналу зв'язку $-\lambda$. Будемо вважати ії однаковою для усіх каналів зв'язку та незмінною в часі, тоді:

$$
\begin{array}{r}
\mathrm{P}\left(\omega_{д}\right)=\frac{\mathrm{x}_{3}}{\mathrm{x}_{3 \max }}\left(1-\left(1-\mathrm{e}^{-\lambda \mathrm{t}}\right)^{\mathrm{x}_{3}}\right) \\
\text { Співмножник } \frac{\mathrm{x}_{3}}{\mathrm{x}_{3 \max }} \text { тут також має зміст }
\end{array}
$$

вагового коефіцієнта та відображує зниження пропускної здатності каналів зв'язку при виході окремих каналів з ладу.

В (1) присутній помножувач $\mathrm{n}_{0 \mathrm{j}} / \mathrm{N}_{0}$, який визначає долю вимог j-ї групи в загальному потоці вимог. У даному випадку $\mathrm{N}_{0}$ має зміст замовлених споживачем номенклатурних аркушів електронних карт, $\mathrm{n}_{0 \mathrm{j}}$ - це реально наявні в базі даних електроні карти; складання повинно проводитися по кількості номенклатурних аркушів електронних карт, а так як ймовірність доставки кожного номенклатурного аркуша електронної карти співпадає i: $\sum_{\mathrm{j}} \mathrm{n}_{0 \mathrm{j}}=\mathrm{x}_{1} ; \mathrm{N}_{0}=\mathrm{x}_{1 \max }$, то у кінцевому варіанті формула для оцінювання надійності функціонування системи топогеодезичного забезпечення прийме вигляд:

$$
\begin{aligned}
& \mathrm{W}=\frac{\mathrm{x}_{1}}{\mathrm{x}_{1 \text { max }}} \frac{1}{\mathrm{t}_{\mathrm{p}}} \int_{0}^{\mathrm{t}_{\mathrm{p}}}\left[\left(1-\mathrm{R}_{0} \mathrm{R}_{1}\right)^{\mathrm{k}}\left(1-\mathrm{R}_{2}\right)\right] \frac{\mathrm{x}_{2}}{\mathrm{x}_{2} \max } \mathrm{x} \\
& \left(1-\left(1-\mathrm{e}^{-\mathrm{ct}}\right)^{\mathrm{x}_{2}}\right) \frac{\mathrm{x}_{3}}{\mathrm{x}_{3 \max }}\left(1-\left(1-\mathrm{e}^{-\lambda \mathrm{t}}\right)^{\mathrm{x}_{3}}\right) \mathrm{dt}
\end{aligned}
$$

Як видно з (10), К еф буде змінюватися від 0 до 1. При цьому надійність дорівнює 100\%, якщо усі канали зв'язку за якими проходить циркуляція топогеодезичної інформації функціонують справно, якщо у банку даних зберігається актуальна топогеодезична інформація, при цьому виключається можливість ураження споживачів противником.

Висновки й перспективи подальших досліджень

Запропонований математичний підхід до 
оцінювання ефективності функціонування системи топогеодезичного забезпечення, як системи масового обслуговування, дозволяє оцінити ймовірність обслуговування споживача відповідною інформацією та встановити, що виконання завдання не буде зірваним через відмови за наступними вхідними параметрами:

наявність у банку даних топогеодезичної

\section{Лimepamypa}

1. Чорнокнижний О. А. Теоретичні основи застосування за призначенням частин та підрозділів топографічної служби. Вісник Київського національного університету імені Тараса Шевченка. Київ: №2 (35), 2016. С. 43-45. 2. Положення про топографічну службу Збройних Сил України. Затв. Наказом ГШ ЗС України від 01.11.2018 р. №377. Київ: ГШ ЗС України. 2018. 3. Астахов А. Д. Пути создания модели оценки інформації на територію, яка необхідна споживачу; доступність та безвідмовна робота каналів зв'язку за якими проходить циркуляція топогеодезичної інформації;

наявність необхідної кількості спеціалістів, які наповнюють бази даних топогеодезичною інформацією відповідно до існуючих вимог до іiі точності, наочності та оперативності.

\title{
МЕТОДИКА ОЦЕНИВАНИЯ НАДЕЖНОСТИ ВЫПОЛНЕНИЯ МЕРОПРИЯТИЙ ПО ТОПОГЕОДЕЗИЧЕСКОМУ ОБЕСПЕЧЕНИЮ
}

\author{
Виталий Владимирович Зуйко (кандидат военных наук, доцент) \\ Сергей Валентинович Зотов \\ Александр Анатолиевич Кошлань
}

\section{Национальный университет обороны Украины имени Ивана Черняховского, Киев, Украина}

В статье рассмотрен поход $\kappa$ оцениванию надежности выполнения мероприятий по топогеодезическому обеспечению путем представления их как системы массового обслуживания, что дает возможность оиенить вероятность обслуживания потребителя соответствующей информацией и установить, что выполнение мероприятия не будет сорванным из-за отказов по следующим входным параметрам: наличие в банке данных топогеодезической информачии на территорию, которая необходима пользователю; доступность и безотказная работа каналов связи по которым происходит ииркуляиия топогеодезической информаиии; наличие необходимого количества специалистов, которые наполняют базы данных топогеодезической информаџией в соответствии с требованиями к ее точности, наглядности и оперативности.

Ключевые слова: топогеодезическое обеспечение; эффективность мероприятий; система массового обслуживания; надежность системы.

\section{METHOD OF ASSESSMENT OF RELIABILITY OF COMPLIANCE OF TOPOGEODESIC SECURITY MEASURES}

\author{
Vitalii Zuiko (Candidate of Technical Sciences, Associate Professor) \\ Serhii Zotov \\ Oleksandr Koshlan
}

\section{National Defence University of Ukraine named after Ivan Cherniakhovsky, Kyiv, Ukraine}

The article discusses the approach to assessing the reliability of execution of topo-geodetic support measures by presenting them as a queuing system, which allows to estimate the probability of servicing the consumer with relevant information and to establish that the task performance will not be impeded due to the failure of the following input parameters: availability of topo-geodetic information in the data bank to the territory required by the consumer; availability and trouble-free operation of the communication channels through which the circulation of topo-geodetic information flows; the availability of the required number of specialists who fill the database with topo-geodetic information in accordance with the existing requirements for its accuracy, clarity and efficiency.

Key words: topogeodetic support; effectiveness of measures; queuing system; system reliability.

\section{References}

1. Chornoknyzhnyj O. A. Teoretychni osnovy zastosuvannja za pryznachennjam chastyn ta pidrozdiliv topoghrafichnoji sluzhby. Visnyk Kyjivsjkogho nacionaljnogho universytetu imeni Tarasa Shevchenka. Kyjiv: №2 (35), 2016. S. 43-45. 2. Polozhennja pro topoghrafichnu sluzhbu Zbrojnykh Syl Ukrajiny. Zatv. Nakazom GhSh ZS Ukrajiny vid 01.11.2018 r. №377. Kyjiv: GhSh ZS Ukrajiny. 2018. 3. Astakhov A. D. Puty sozdanyja modely ocenky эffektyvnosty systemы topogheodezycheskogho obespechenyja vojsk. Moskva: RYO VTS. 1984. 185 s. 4.Smalj S., Chornoknyzhnyj O. Pytannja vyznachennja racionaljnogho sposobu vykonannja zavdanj navighacijnogho zabezpechennja. Trudy akademiji. Nacionaljna akademija oborony Ukrajiny. Kyjiv: NAOU. 2005. S. 136-139. 